Pacific Journal of Mathematics

NEW DIAGRAM PROOFS OF THE HAUSDORFF-YOUNG
THEOREM AND YOUNG'S INEQUALITY 


\title{
NEW DIAGRAM PROOFS OF THE HAUSDORFF-YOUNG THEOREM AND YOUNG'S INEQUALITY
}

\author{
ROOSEVELT GeNTRY
}

\begin{abstract}
In this paper, the diagram proof of Riesz's Theorem proved by the author is used to give new diagram proofs for the classical Hausdorff-Young Theorem, and Young's Inequality, where Fourier transforms and convolutions are used respectively.
\end{abstract}

I. Introduction. ${ }^{1}$ Very often, the same operator is investigated on several different function spaces. Thus, it is valuable to have theorems which give relationships between properties of the same operator considered in different function spaces. The well-known Marcel Riesz interpolation theorem [11] which was published in 1926 is a nontrivial example of such a theorem.

Since 1926, much work has been done in interpolation theory by A. P. Calderon in 1964, Lions-Peetre [9] in 1964, and M. Schechter in 1967.

More recently, V. Williams [16], in 1971, defined a generalized interpolation space, $X_{(T, C)}$, which generalizes each of the above-mentioned interpolation spaces. Also, a generalized interpolation theorem is proved in [16] which generalizes the Calderon, Lions-Peetre, and Schechter interpolation theorems.

The classical theorems of Riesz and Marcinkiewicz follow from interpolation theory, and there are many applications in differential equations, Banach algebras, and nonlinear, complex, and compact interpolation theories (see $[13,14,3,7,8$, and 5]).

We now give a definition:

Definition. A compatible triplet $\left\{X_{0}, X_{1}, \mathscr{Z}\right\}$ consists of two Banach spaces $X_{0}$ and $X_{1}$ which are continuously embedded in a Hausdorff topological vector space $\mathscr{X}$.

$s_{x}=s\left(P_{0}, E_{0}, X_{0}, P_{1}, E_{1}, X_{1}\right)$ denotes the Lions-Peetre [9] interpolation space which is also a generalized interpolation space [16].

In this paper, the diagram proof of Riesz's theorem proved by the author [6] is used to give new diagram proofs for the classical Hausdorff-Young theorem, and Young's inequality, where Fourier transforms and convolutions are used respectively.

II. Diagram proof of the Hausdorff-Young Theorem. As a corollary of the author's diagram proof [6] of Riesz's theorem, we

\footnotetext{
1 Terms used in the introduction will be defined in the paper.
} 
get the classical Hausdorff-Young theorem. The corollary is significant because we give a new diagram proof of this classical theorem.

First, we give our classical notation and state a classical lemma.

$L^{P}\left(R^{1}\right), 1 \leqq P \leqq \infty$, denotes functions defined on $R^{1}$ which have values in the complex numbers, $C$, with the usual norm, and $m$ denotes the Lebesgue measure on $R^{1}$ divided by $\sqrt{2 \pi}$.

We have

$$
\int_{-\infty}^{\infty} f(x) d m(x)=\frac{1}{\sqrt{2 \pi}} \int_{-\infty}^{\infty} f(x) d x \text {, where } d x \text { refers to }
$$

Define $\hat{f}$ by

the ordinary Lebesgue measure.

$$
\hat{f}(t)=\int_{-\infty}^{\infty} f(x) e^{-i x t} d m(x), \quad t \in R^{1} .
$$

If $f \in L^{1}\left(R^{1}\right)$, the integral in Line (4) is well defined for every real $t$. The function $\hat{f}$, the Fourier transform of $f$, is denoted by $F(f)$, that is, $F$ sends $f$ to $\hat{f}$.

Since the Lebesgue measure of $R^{1}$ is infinite, $L^{2}\left(R^{1}\right)$ is not a subset of $L^{1}\left(R^{1}\right)$, and the definition of the Fourier transform is not directly applicable for every $f \in L^{2}\left(R^{1}\right)$. However, the definition does apply if $f \in L^{1}\left(R^{1}\right) \cap L^{2}\left(R^{1}\right)$, for in this case $\hat{f} \in L^{2}\left(R^{1}\right)$. In fact, $\|\hat{f}\|_{L^{2}\left(R^{1}\right)}=$ $\|f\|_{L^{2}\left(R^{1}\right)}$. This isometry of $L^{1}\left(R^{1}\right) \cap L^{2}\left(R^{1}\right)$ into $L^{2}\left(R^{1}\right)$ extends to an isometry of $L^{2}\left(R^{1}\right)$ onto $L^{2}\left(R^{1}\right)$, and this extension defines the Fourier transform (sometimes called the Plancherel transform) of every $f \in L^{2}\left(R^{1}\right)$. The $L^{2}\left(R^{1}\right)$-theory has more symmetry than $L^{1}\left(R^{1}\right)$. In $L^{2}\left(R^{1}\right), f$ and $\hat{f}$ play exactly the same role.

We now state some classical results:

LEMma. The Fourier transform map, $F: L^{1}\left(R^{1}\right) \rightarrow L^{\infty}\left(R^{1}\right)$ where $F(f)=\widehat{f}$, for $f \in L^{1}\left(R^{1}\right)$ is bounded, linear, and for every $f \in L^{1}\left(R^{1}\right)$

$$
\|F(f)\|_{L^{\infty}\left(R^{1}\right)}=\|\hat{f}\|_{L^{\infty}\left(R^{1}\right)} \leqq\|f\|_{L^{1}\left(R^{1}\right)} .
$$

Therefore, $\|F\|_{B\left(L^{1}\left(R^{1}\right), L^{\infty}\left(R^{1}\right)\right)} \leqq 1$.

Plancherel Theorem. One can associate to each $f \in L^{2}\left(R^{1}\right)$ a function $\hat{f} \in L^{2}\left(R^{1}\right)$ such that:

(a) If $f \in L^{1}\left(R^{1}\right) \cap L^{2}\left(R^{1}\right)$, then $\hat{f}$ is the previously defined Fourier transform of $f$.

(b) For every $f \in L^{1}\left(R^{1}\right),\|\hat{f}\|_{L^{2}\left(R^{1}\right)}=\|f\|_{L^{2}\left(R^{1}\right)}$.

(c) The map $F: L^{2}\left(R^{1}\right) \rightarrow L^{2}\left(R^{1}\right)$, where $F(f)=\hat{f}$, for each $f \in L^{2}\left(R^{1}\right)$ is an isomorphism of $L^{2}\left(R^{1}\right)$ onto $L^{2}\left(R^{1}\right)$. In particular, $F$ is bounded, linear, and by Part (b),

$$
\|F\|_{B\left(L^{2}\left(R^{1}\right), L^{2}\left(R^{1}\right)\right)}=1 .
$$


Note: Since $L^{1}\left(R^{1}\right) \cap L^{2}\left(R^{1}\right)$ is dense in $L^{2}\left(R^{1}\right)$, Parts (a) and (b) determine the map $F$ uniquely.

Hausdorff-Young Theorem. With the above notation, let $1 \leqq$ $P \leqq 2$, let $1 \leqq q \leqq \infty$ be such that $1 / P+1 / q=1$; if $f \in L^{P}\left(R^{1}\right)$ then

$$
\|\hat{f}\|_{L^{q}\left(R^{1}\right)} \leqq\|f\|_{L^{P}\left(R^{1}\right)} .
$$

We now state our main theorem:

THeOREM. If $1<P<2$, the Hausdorff-Young Theorem follows from the diagram proof Riesz's Theorem.

Proof. First, we consider a commutative diagram (see below).

By the author's work [4], for any fixed $0<s<1$, there exist $E_{0}$ and $E_{1}$ in $R^{1}$ such that $E_{0} \cdot E_{1}<0$ and $s=E_{0} /\left(E_{0}-E_{1}\right)$.

Let $P_{0}=1, P_{1}=2, q_{0}=\infty, q_{1}=2$, so $P_{i} \leqq q_{i}, i=0,1$. Let $P$ and $q$ satisfy

$$
\frac{1}{P}=\frac{1-s}{P_{0}}+\frac{s}{P_{1}}, \quad \frac{1}{q}=\frac{1-s}{q_{0}}+\frac{s}{q_{1}} .
$$

From previous work [4], $\left\{L^{1}\left(R^{1}\right), L^{2}\left(R^{1}\right), L_{1 \mathrm{oc}}^{1}\left(R^{1}\right)\right\}$ and $\left\{L^{\infty}\left(R^{1}\right), L^{2}\left(R^{1}\right)\right.$, $\left.L_{\text {loc }}^{1}\left(R^{1}\right)\right\}$ are compatible triplets; therefore the sums in the diagram make sense.

From above work, all spaces in the diagram are Banach. Let $L=F$ be the Fourier transform map as defined above.

By the lemma and Plancherel's theorem,

(9) $L \in B\left(L^{1}\left(R^{1}\right), L^{\infty}\left(R^{1}\right)\right)$ and $L \in B\left(L^{2}\left(R^{1}\right), L^{2}\left(R^{1}\right)\right)$, with respective norms $N_{0}$ and $N_{1}$, where $N_{0} \leqq 1, N_{1}=1$.

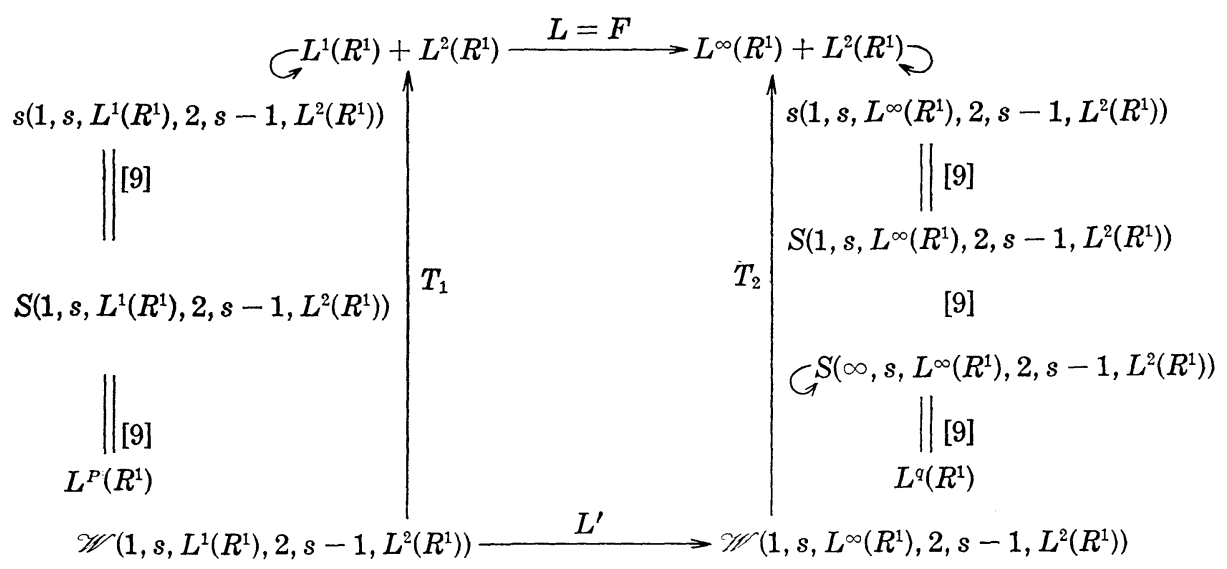


From previous work [4], $L$ is a bounded linear map from $L^{1}\left(R^{1}\right)+L^{2}\left(R^{1}\right)$ to $L^{\infty}\left(R^{1}\right)+L^{2}\left(R^{1}\right)$.

$L^{\prime}, T_{1}$, and $T_{2}$ are defined as follows:

$$
L^{\prime}(f)=L \circ f, \quad T_{1}(f)=\sum_{-\infty}^{\infty} f_{n}, \quad T_{2}(g)=\sum_{-\infty}^{\infty} g_{n},
$$

where $f \in \mathscr{W}\left(1, s, L^{1}\left(R^{1}\right), 2, s-1, L^{2}\left(R^{1}\right)\right)$ and $g \in \mathscr{W}\left(1, s, L^{\infty}\left(R^{1}\right), 2, s-1\right.$, $\left.L^{2}\left(R^{1}\right)\right)$, that is,

$$
\begin{aligned}
& f: z=\{0, \pm 1, \pm 2, \cdots\} \longrightarrow L^{1}\left(R^{1}\right)+L^{2}\left(R^{1}\right), \\
& g: z \longrightarrow L^{\infty}\left(R^{1}\right)+L^{2}\left(R^{1}\right) .
\end{aligned}
$$

$L^{\prime}, T_{1}$, and $T_{2}$ are bounded linear maps. By the definition of $L^{\prime}$, we have $L T_{1}=T_{2} L^{\prime}$.

By Riesz's theorem

$$
L \in B\left(L^{P}\left(R^{1}\right), L^{q}\left(R^{1}\right)\right), \text { and by Line (9), }
$$

$\|L\| \leqq \max \left\{N_{0}, N_{1}\right\} \leqq \max \{1,1\}=1$. Therefore,

$$
\|L\|_{B\left(L^{P}\left(R^{1}\right), L^{q}\left(R^{1}\right)\right)} \leqq 1 .
$$

By the definition of $P$ and $q$,

$$
\begin{aligned}
& \frac{1}{P}=\frac{1-s}{P_{0}}+\frac{s}{P_{1}}=\frac{1-s}{1}+\frac{s}{2}=1-s+\frac{s}{2}=1-\frac{s}{2}, \text { and } \\
& \frac{1}{q}=\frac{1-s}{q_{0}}+\frac{s}{q_{1}}=0+\frac{s}{2}=\frac{s}{2} .
\end{aligned}
$$

Therefore, $1 / P+1 / q=1$.

From above, $s=E_{0} /\left(E_{0}-E_{1}\right) \in(0,1)$.

Note: If $s=0$, then $P=1$; if $s=1$ then $P=2 . s \in(0,1)$ implies $0<s / 2<1 / 2$, which implies $1>1-s / 2>1 / 2$, which implies $1>1 / P>1 / 2$, which implies $1<P<2$.

So, $P$, as defined in Line (12), will always be such that $1<P<2$.

From above,

$$
L=F \in B\left(L^{P}\left(R^{1}\right), L^{q}\left(R^{1}\right)\right),
$$

therefore, for every $f \in L^{P}\left(R^{1}\right)$,

$$
\|L(f)\|_{L^{q}\left(R^{1}\right)}=\|F(f)\|_{L^{q}\left(R^{1}\right)} \leqq 1 \cdot\|f\|_{L^{P}\left(R^{1}\right)}=\|f\|_{L^{P}\left(R^{1}\right)} .
$$

By definition,

$$
F(f)=\hat{f},
$$

therefore, for every $f \in L^{P}\left(R^{1}\right)$, we have

$$
\|\hat{f}\|_{L^{q}\left(R^{1}\right)} \leqq\|f\|_{L^{P}\left(R^{1}\right)},
$$

so the Hausdorff-Young theorem holds if $1<P<2$. 
III. A diagram proof of Young's Inequality. Next, we show that as a consequence of the diagram proof of Riesz's theorem, we get an inequality of W. H. Young.

Some classical results are:

Definition. Let $f$ and $g$ be two $m$-measurable functions on $R^{1}$ such that $f(x-y), g(y)$ is $m$-integrable on $R^{1}, x, y \in R^{1}$; the convolution, $f * g$, of $f$ and $g$ at point $x$ is defined by

$$
(f * g)(x)=\int_{-\infty}^{\infty} f(x-y) g(y) d m(y), \quad x \in R^{1} .
$$

Young's Inequality. Suppose that

$$
1 \leqq P \leqq \infty, 1 \leqq q \leqq \infty, \frac{1}{r}=\frac{1}{P}+\frac{1}{q}-1 \geqq 0 .
$$

Let $f \in L^{P}\left(R^{1}\right), g \in L^{q}\left(R^{1}\right)$. Then

$$
\|f * g\|_{L^{r}\left(R^{1}\right)} \leqq\|f\|_{L^{\left.P_{(} R^{1}\right)}} . \quad\|g\|_{L^{q}\left(R^{1}\right)} .
$$

Our main theorem for this section is:

THEOREM. Young's Inequality above follows from the diagram proof of Riesz's Theorem if $1<P, q<\infty$, and $1 / r=1 / P+1 / q-1>0$.

Proof. Let $1<P, q<\infty$, be such that $1 / P+1 / q-1>0$, let $1 / r=1 / P+1 / q-1$, let $P^{\prime}$ be such that $1 / P+1 / P^{\prime}=1$.

For $q_{0}=1, q_{1}=P^{\prime}, r_{0}=P, r_{1}=\infty$, we show that there is an $s$ such that $0<s<1$, and these equations hold:

and

$$
\frac{1}{q}=\frac{1-s}{q_{0}}+\frac{s}{q_{1}}=\frac{1-s}{1}+\frac{s}{P^{\prime}},
$$

$$
\frac{1}{r}=\frac{1-s}{r_{0}}+\frac{s}{r_{1}}=\frac{1-s}{P}+0=\frac{1-s}{P}
$$

Now,

$$
\frac{1}{q}=\frac{1-s}{1}+\frac{s}{P^{\prime}}=\frac{P^{\prime}(1-s)+s}{P^{\prime}}
$$

Thus,

and

$$
\begin{aligned}
& \frac{P^{\prime}}{q}=P^{\prime}(1-s)+s, \\
& P^{\prime}-P^{\prime} s+s=\frac{P^{\prime}}{q},
\end{aligned}
$$

$$
s\left(1-P^{\prime}\right)=\frac{P^{\prime}}{q}-P^{\prime} .
$$


Thus, $s=\left(P^{\prime} / q-P^{\prime}\right) /\left(1-P^{\prime}\right), P^{\prime} \neq 1$ since $1<P<\infty$. Thus, $s=$ $(1 / q-1) /\left(1 / P^{\prime}-1\right)>0$, since $q>1,1<P<\infty$, and $P^{\prime}>1$.

Now, $1 / q-1>-1 / P, 1 /(-1 / P)<0 ;$ thus, $(1 / q-1) /(-1 / P)<$ $(-1 / P) /(-1 / P)=1,-1 / P=1 / P^{\prime}-1$, thus, $0<s=(1 / q-1) /(-1 / P)<1$.

We show this same $0<s<1$ works for $r$, where

$$
\frac{1}{r}=\frac{1-s}{r_{0}}+\frac{s}{r_{1}}=\frac{1-s}{P}+0=\frac{1-s}{P} .
$$

Also, $1 / P+1 / q-1=(1-s) / P$

$$
\begin{aligned}
\frac{1}{r} & =\frac{1}{P}+\frac{1}{q}-1=\frac{1}{P}+\left(\frac{1-s}{1}+\frac{s}{P^{\prime}}\right)-1 \\
& =\frac{1}{P}+\left[1-s+s\left(1-\frac{1}{P}\right)-1\right] \\
& =\frac{1}{P}+\left[1-s+s-\frac{s}{P}-1\right]=\frac{1-s}{P} .
\end{aligned}
$$

As shown on the preceding page, for $0<s<1$ fixed, there exist reals $E_{0}$ and $E_{1}$ such that $E_{0} \cdot E_{1}<0$ and $s=E_{0} /\left(E_{0}-E_{1}\right)$.

Let $f \in L^{P}\left(R^{1}\right)$ be fixed, once chosen. Let $g \in L^{1}\left(R^{1}\right)$, and $g \in L^{P^{\prime}}\left(R^{1}\right)$, define $L$ by $L(g)=f * g$.

From classical work,

$$
L \in B\left(L^{1}\left(R^{1}\right), L^{P}\left(R^{1}\right)\right), \quad L \in B\left(L^{P^{\prime}}\left(R^{1}\right), L^{\infty}\left(R^{1}\right)\right),
$$

where

$$
\|L\|_{B\left(L^{1}\left(R^{1}\right), L^{P}\left(R^{1}\right)\right)} \leqq\|f\|_{L^{P}\left(R^{1}\right)}
$$

and

$$
\|L\|_{B\left(L^{P}\left(R^{1}\right), L^{\infty}\left(R^{1}\right)\right)} \leqq\|f\|_{L^{P}\left(R^{1}\right)} .
$$

Under the above conditions, we now consider a commutative diagram:

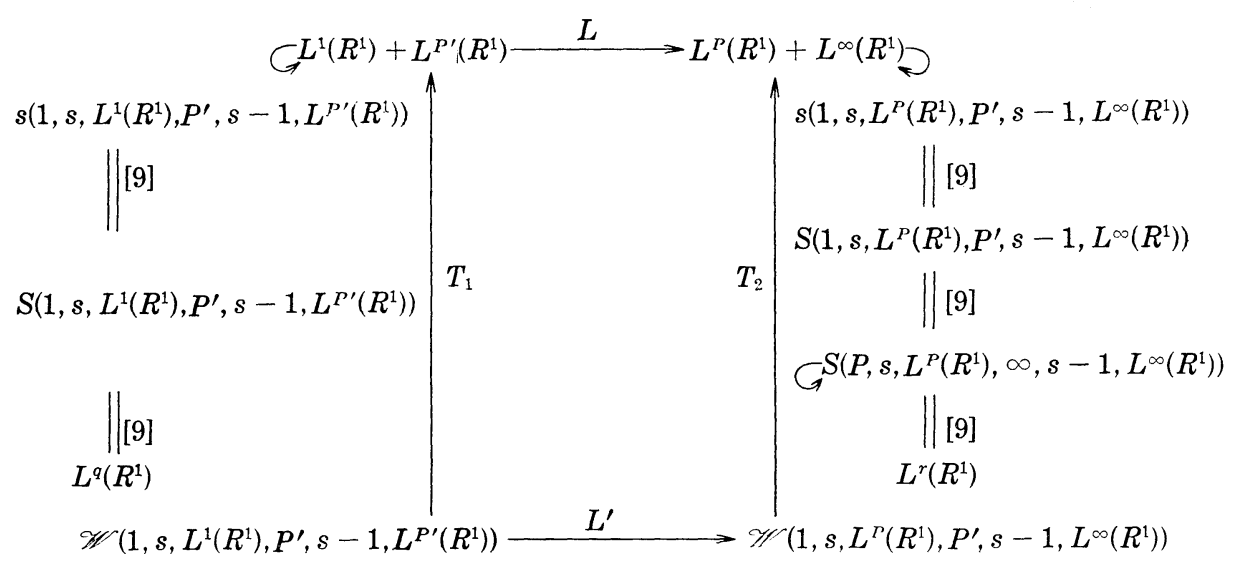


As above,

and

$$
\left\{L^{1}\left(R^{1}\right), L^{I^{\prime \prime}}\left(R^{1}\right), L_{1 \mathrm{oc}}^{1}\left(R^{1}\right)\right\}
$$

$$
\left\{L^{P}\left(R^{1}\right), L^{\infty}\left(R^{1}\right), L_{1 \circ \mathrm{co}}^{1}\left(R^{1}\right)\right\}
$$

are compatible triplets. Therefore, the sums in the diagram make sense.

Also, all spaces are Banach in diagram, and $L$ defines a linear map from $L^{1}\left(R^{1}\right)+L^{P^{\prime}}\left(R^{1}\right)$ to $L^{P}\left(R^{1}\right)+L^{\infty}\left(R^{1}\right)$.

The bounded linear maps $L^{\prime}, T_{1}$, and $T_{2}$ are defined as above, and $L T_{1}=T_{2} L^{\prime}$.

From Riesz's theorem,

$$
L \in B\left(L^{q}\left(R^{1}\right), L^{r}\left(R^{1}\right)\right),
$$

with

$$
\|L\| \leqq \max \left\{\|f\|_{L^{P^{\prime}\left(R^{1}\right)}},\|f\|_{L^{P}\left(R^{1}\right)}\right\}=\|f\|_{L^{P^{\prime}\left(R^{1}\right)}} .
$$

Therefore, for any $g \in L^{q}\left(R^{1}\right)$, we have

$$
\|L(g)\|_{L^{r}\left(R^{1}\right)} \leqq\|f\|_{L^{P}\left(R^{1}\right)} \cdot\|g\|_{L^{q}\left(R^{1}\right)}, \text { where } f \text { is fixed. }
$$

By definition of $L, L(g)=f * g$, therefore, for any $g \in L^{q}\left(R^{1}\right)$, we have

$$
\|f * g\|_{L^{r}\left(R^{1}\right)} \leqq\|f\|_{L^{P}\left(R^{1}\right)} \cdot\|g\|_{L^{q}\left(R^{1}\right)},
$$

and therefore Young's inequality holds.

\section{REFERENCES}

1. R. E. Edwards, Fourier Series, A Modern Introduction, Vol. I, Holt, Rinehart and Winston, New York, 1967.

2. - Fourier Series, A Modern Introduction, Vol. II, Holt, Rinehart and Winston, New York, 1967.

3. R. Genrty, Banach algebra interpolation theory, Annales de la Société Scientifique de Bruxelles, T. 93, I (1979), 55-67.

4. — Compact Interpolation Between Banach Spaces, Ph. D. Dissertation, Rutgers University Library, New Brunswick, New Jersey, 1974.

5 - A generalization of theorems of Krasnoselskii and Juberg. J. Math. Anal. Appl. 76 No. 2 (1980), 369-377.

6. - A new diagram proof of the classical Riesz interpolation theorem, 1979 (to appear).

7. - Nonlinear weak generalized interpolation, Riv. Mat. Univ. Parma 6 No. 4 (1980).

8. - Operators from Banach spaces to complex interpolation spaces, 1978 (to appear).

9. J. L. Lions and J. Peetre, Sur une clusse d'espaces d'interpolation, Inst. Hautes Études Sci. Publ. Math. No. 19 (1964), 5-68.

10. J. Marcinkiewicz, Sur l'interpolation d'operateurs, C. R. Acad. Sci. Paris, 208 (1939), 1272-1273. 
11. M. Riesz, Sur les maxima des formes biliaries et sur les fonctionnelles lineaires, Acta Math., 49 (1926), 465-497.

12. W. Rudin, Real and Complex Analysis, Mc-Graw Hill, New York, 1966.

13. M. Schechter, On the theory of differential boundary problems, Illinois J. Math., 7 No. 2 (1963), 232-245.

14. — On $L^{P}$ estimates and regularity, Amer. J. Math., 85 (1963), 1-13.

15. E. M. Stein and G. Weiss, Introduction to Fourier Analysis on Euclidean Spaces, Princeton Univ. Press, Princeton, 1971.

16. V. Williams, Generalized interpolation spaces, Trans. Amer. Math. Soc., 156 (1971), 309-334.

17. A. Zygmund, Trigonometric Series, Vol. II, Cambridge Univ. Press, London, 1959.

Received November 19, 1979. This paper was made possible in part by fellowships received from the Southern Fellowships Fund of Atlanta, Georgia. The author, however, and not The Southern Fellowships Fund, is completely responsible for the statements made herein and for their publication.

Jackson State University

JACKSON, MS 39217 


\section{PACIFIC JOURNAL OF MATHEMATICS}

\section{EDITORS}

DONALD BABBITT (Managing Editor)

University of California

Los Angeles, California 90024

Hugo RossI

University of Utah

Salt Lake City, UT 84112

C. C. MOORE and ANDREW OGG

University of California

Berkeley, CA 94720

\section{J. DugundJI}

Department of Mathematics University of Southern California Los Angeles, California 90007

R. Finn and J. Milgram Stanford University

Stanford, California 94305

\section{ASSOCIATE EDITORS}
R. ARENS
E. F. BeCKENBACH
B. H. Neumann
F. WoLF
K. YoSHIDA

\section{SUPPORTING INSTITUTIONS}

UNIVERSITY OF ARIZONA

UNIVERSITY OF BRITISH COLUMBIA

CALIFORNIA INSTITUTE OF TECHNOLOGY

UNIVERSITY OF CALIFORNIA

MONTANA STATE UNIVERSITY

UNIVERSITY OF NEVADA, RENO

NEW MEXICO STATE UNIVERSITY

OREGON STATE UNIVERSITY
UNIVERSITY OF OREGON

UNIVERSITY OF SOUTHERN CALIFORNIA

STANFORD UNIVERSITY

UNIVERSITY OF HAWAII

UNIVERSITY OF TOKYO

UNIVERSITY OF UTAH

WASHINGTON STATE UNIVERSITY

UNIVERSITY OF WASHINGTON 


\section{Pacific Journal of Mathematics}

\section{Vol. 97, No. $1 \quad$ January, 1981}

Charles A. Asmuth and Joe Repka, Tensor products for $S L_{2}(\mathfrak{k})$. II.

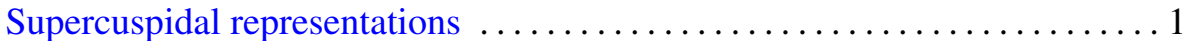

Joseph Barback, On finite sums of regressive isols . ................. 19

Matthew G. Brin and Daniel Russell McMillan, Jr., Generalized

three-manifolds with zero-dimensional nonmanifold set ............29

Kun Soo Chang, Converse measurability theorems for Yeh-Wiener space . . . 59

Christopher Brian Croke, A "maximal torus" type theorem for complete

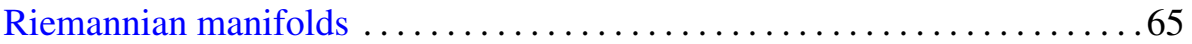

Gustave Adam Efroymson, Sums of squares in planar Nash rings . . . . . . 75

John Robert Fisher, Axiomatic radical and semisimple classes of rings . . . .81

Betty Kvarda, Consecutive integers for which $n^{2}+1$ is composite .......93

Roosevelt Gentry, New diagram proofs of the Hausdorff-Young theorem

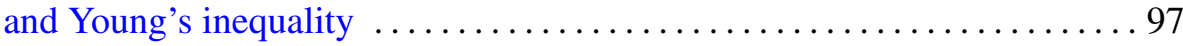

Patrick M. Gilmer, Topological proof of the $G$-signature theorem for $G$

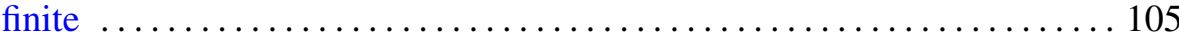

Chung Wei Ha, A noncompact minimax theorem .................. 115

James J. Hebda, Manifolds admitting taut hyperspheres ................ 119

Takayuki Kawada, Sample functions of Pólya processes ............. 125

Peter K. F. Kuhfittig, Common fixed points of nonexpansive mappings by

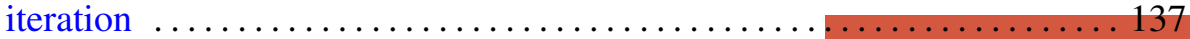

James Thomas Loats and Judith Roitman, Almost rigid Hopfian and dual

Hopfian atomic Boolean algebras .......................... 141

Roger McCann, On embedding semiflows into a radial flow on $l_{2} \ldots \ldots \ldots 151$

John McDonald, Closed orbits of convex sets of operators on the disk

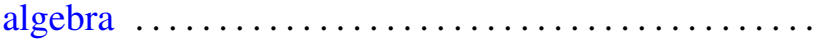

Mark D. Meyerson, Convexity and the table theorem .............. 167

Arnold William Miller, Generic Souslin sets . . . . . . . . . . . . . . . . 171

Takemi Mizokami, On the closed images of paracomplexes $\ldots \ldots \ldots \ldots \ldots 3$

Jagannadham Venkata Pakala and Thomas Stephen Shores, On

compactly packed rings $\ldots \ldots \ldots \ldots \ldots \ldots \ldots \ldots \ldots$

Andrew Pletch, Strong completeness in profinite groups

Wilbur Carrington Whitten, Inverting double knots

James Juei-Chin Yeh, Existence of strong solutions for stochastic

differential equations in the plane 